Dicle University Journal of Engineering (DUJE)

Araştırma Makalesi / Research Article

\title{
Temiz Su Koşulları Altında Dairesel Köprü Ayaklarının Etrafındaki Nihai Oyulma Derinliklerinin Deneysel Araştırılması
}

\section{Experimental Investigation of Final Scour Depths Around Circular Bridge Piers Under Clear-Water Conditions}

\section{Fırat Gümgüm ${ }^{1 *}$, Ayşegül Ö. Aksoy², M. Şükrü Güney ${ }^{3}$}

${ }^{1}$ Dicle Üniversitesi, İnşaat Mühendisliği Bölümü, Diyarbakır, firat.gumgum@dicle.edu.tr

2 Dokuz Eylül Üniversitesi, İnşaat Mühendisliği Bölümü, İzmir, aysegul.ozgenc@deu.edu.tr

${ }^{3}$ İzmir Ekonomi Üniversitesi, İnşaat Mühendisliği Bölümü, İzmir, sukru.guney@ izmirekonomi.edu.tr

\begin{tabular}{|c|c|}
\hline \multicolumn{2}{|c|}{ MAKALE BİLGİLERİ } \\
\hline \multicolumn{2}{|c|}{ Makale geçmişi: } \\
\hline Geliş: & 27 Haziran 2019 \\
\hline Düzeltme: & 5 Temmuz 2019 \\
\hline Kabul: & 8 Ağustos 2019 \\
\hline
\end{tabular}

Köprü ayağı, yerel oyulma, temiz su oyulması, kararlı akım

\begin{abstract}
ÖZET
Bu deneysel çalışmada, TÜBİTAK 109M637 projesi kapsamında inşa edilen hareketli tabanlı doğrusal kanalda kararlı akım şartlarında dairesel kesitli köprü ayakları etrafındaki nihai temiz su oyulması incelenmiştir. Deneysel çalışmada 4 farklı boyutlu dairesel köprü ayağı ve 3,47 mm ortalama tane çapına sahip üniform taban malzemesi kullanılmıştır. Ultrasonik hız profilleyicisi yardımıyla ölçülen oyulma derinlikleri, literatürdeki mevcut bağıntılardan elde edilen oyulma derinlikleri ile karșılaștırılmıș ve oyulma derinliği ile ilișkili bazı parametrelerin oyulma derinliğine olan etkisi incelenmiștir. Ceșitli regresyon analizleri sonucu nihai temiz su oyulma derinliğini tahmin eden bir bağıntı önerilmiş ve istatistiksel olarak anlamlı parametreler elde edilmiştir. En yüksek oyulma derinliğinin ayağın memba bölgesinde meydana geldiği gözlenmiştir. Akım şiddeti, yoğunluk farkı esaslı dane Froude sayısı ve köprü ayak çapı arttıkça oyulma derinliğinin arttığı tespit edilmiştir.
\end{abstract}

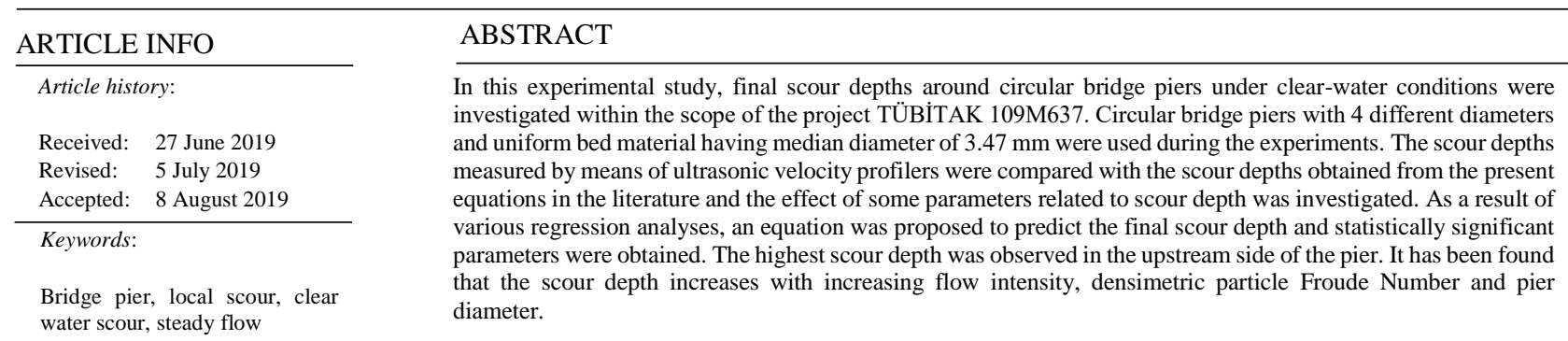




\section{Giriş}

Bugüne kadar çeşitli araştırmacılar tarafından köprü ayakları etrafında meydana gelen temiz su oyulması konusunda birçok araştırma yapılmıştır. Köprü ayakları etrafindaki yerel oyulmanın gelişimi karmaşık bir süreçtir ve bu konuda çok fazla çalışma olmasına rağmen hâlâ araştırmacıları ilgilendirmektedir.

Melville ve Sutherland (1988) önceki çalışmalardan elde edilen deneysel verileri kullanarak üniform dağılımlı katı madde (sediment) için hem temiz su hem de hareketli taban nihai oyulma derinliklerini tahmin eden bir denklem önermișlerdir. Melville (1997) bu çalışmaları farklı şekillerde köprü orta ve yan ayakları için üniform ve üniform olmayan sediment kullanarak sürdürmüştür. Richardson and Davis (2001), geçmişte yapılan deneysel çalışmalara ait verileri değerlendirerek, farklı tipte köprü orta ayakları etrafinda nihai temiz su ve hareketli taban oyulmasinı tahmin eden bir bağıntı önermişlerdir. Oliveto ve Hager (2002), üniform ve üniform olmayan taban malzemesi kullanarak dairesel köprü orta ayakları etrafında meydana gelen temiz su oyulmasinı deneysel olarak incelemiş, çalışmalarının sonucunda temiz su oyulması şartlarında meydana gelen yerel oyulmanın zamana bağlı değişimini veren bir bağıntı önermişlerdir. Sheppard vd. (2004), üniform taban malzemesi kullanarak köprü orta ayakları etrafinda meydana gelen temiz su oyulmasını deneysel olarak incelemiş ve nihai oyulma derinliğini veren bir bağıntı önermişlerdir. Oliveto ve Hager (2005), köprü orta ve yan ayakları ve mahmuzlar etrafinda oluşan yerel oyulmaları deneysel olarak incelemişlerdir. Ayrıca köprü orta ayakları etrafında taşkın hidrografları sırasında meydana gelen yerel oyulmanın zamana bağlı değişimini veren bir yöntem önermişlerdir. Kothyari vd. (2007), temiz su oyulmasının zamana bağlı gelişimini hesaplamak için yeni bir bağıntı geliştirmişlerdir. Lai vd. (2009), kararlı ve kararsız akım koşullarında, üniform ve üniform olmayan taban malzemesi kullanarak köprü orta ayağ 1 etrafindaki temiz su oyulmasının zamana bağlı değişimini tahmin eden bir yöntem önermiştir.
$\mathrm{Bu}$ çalışmada, dairesel köprü ayakları etrafında meydana gelen temiz su oyulması, deneysel olarak araștırılmıș ve literatürdeki mevcut bağıntılarla karşılaştırılmıştır.

\section{Köprü Ayakları Etrafındaki Yerel Oyulma}

Oyulma kavramı, genel olarak taban malzemesinin tabandan veya tabana inşa edilmiş bir yapının etrafından ayrılması ve sürüklenmesi olarak tanımlanır. Yerel oyulma ise oyulmanın direkt olarak akıma müdahale eden bir yapıdan (köprü ayağı, köprü yan ayağı, açık kanal birleşimi vs) kaynaklanması ile ifade edilir.

Yaklaşan akım köprü ayağına ulaştığında ayağın memba kenarında kabarır ve bu noktada yüksek basınç oluşturur. Yüzeydeki yüksek basınçtan dolayı tabana doğru dikey bir akım oluşur. Chiew (1984) ve Raudkivi (1986), bu dikey akımı yerel oyulmanın başlıca nedeni olarak tanımlamıștır. Yaklaşan akımın dikey akım ile etkileşime girmesi sonucu ise at nalı çevrintileri meydana gelir. Dikey akımdan kaynaklanan ve başlangıçta küçük olan oyulma çukuru, at nalı çevrintilerinin oluşması ile birlikte hızla genişler ve oyulma çukuru genişledikçe at nalı çevrintilerinin etkisi azalmaya başlar (Melville, 1975). Kısacası, oyulmayı ilk olarak yüzeyden tabana doğru hareket eden dikey akım başlatır ve meydana getirdiği küçük çukurun içinde gelişen at nalı çevrintileri ile birlikte oyulma çukuru önemli ölçüde genişler. Bununla birlikte ayağın yanlarından süzülen akım ise ayağın mansap bölgesinde görece daha zayıf olan kuyruk çevrintilerini oluşturur. Melville (1975), kuyruk çevrintilerini taban malzemesini mansap bölgesine çeken bir elektrikli süpürgeye benzetmiştir.

Oyulmalar, tabanda malzeme hareketi olup olmamasına göre iki ayrı başlık altında incelenmektedir. Akımın tabanda yarattığı kayma gerilmesinin taban malzemesinin kritik kayma gerilmesinden küçük olması durumunda tabanda malzeme hareketi meydana gelmez. Bu koşul altında meydana gelen oyulmalar temiz su oyulması olarak adlandırılır. Akımın tabanda yarattığ kayma gerilmesinin taban malzemesinin kritik kayma gerilmesinden büyük olması durumunda ise tabanda malzeme hareketi meydana gelir ve taşınan malzeme, oyulma çukurunu doldurmaya başlar. $\mathrm{Bu}$ koşul altında 
meydana gelen oyulmalar ise hareketli taban oyulması olarak adlandirılmaktadır. $\mathrm{Bu}$ çalışmada dairesel en kesitli köprü orta ayakları etrafinda meydana gelen temiz su oyulmaları deneysel olarak incelenmiştir. boyunca devam etmesi gerekiyor olsa da Yanmaz (2002), laboratuvar ortamında gerçekleştirilen deneylerde bu sürelerin çok uzun olduğunu, Froude modelinde 1/50 ölçekte inşa edilen bir kanalda 50 saat süren bir deneyin doğada 354 saate tekabül edeceğini belirtmiştir.

Tablo 1. Temiz su denge oyulma derinliğini tahmin eden bağıntılar

Table 1. Equations predicting the equilibrium clear-water scour depth

\begin{tabular}{ll}
\hline Araştırmacı & Bağıntı \\
\hline Laursen (1958) & $\frac{d_{s}}{b}=1,34\left(\frac{y}{b}\right)^{0,5}$ \\
Hancu (1971) & $\frac{d_{s}}{b}=2,42\left(\frac{y}{b}\right)^{1 / 3} F r^{2 / 3}$ \\
Breusers vd. (1977) & $\frac{d_{s}}{b}=2 \tanh \left(\frac{y}{b}\right)^{0,471}$ \\
Günyaktı (1988) & $\frac{d_{s}}{b}=1,183\left(\frac{y}{b}\right)^{0,471}$ \\
Yanmaz (1989) & $\frac{d_{s}}{b}=0,85\left(\frac{y}{b}\right)^{0,686}$ \\
Melville (1977) & $\frac{d_{s}}{}=K_{y W} K_{I} K_{d} K_{s} K_{\theta} K_{G}$ \\
Richardson ve Davis (2001) & $\frac{d_{s}}{b}=2 K_{1} K_{2} K_{3} K_{4}\left(\frac{y}{b}\right)^{0,35} F r^{0,43}$ \\
Oliveto ve Hager (2002) & $\frac{d_{s}}{z_{R}}=0,068 \sigma_{g}^{-1 / 2} F_{d}^{1,5} \log (T)$ \\
Sheppard vd. (2004) & $\frac{d_{s}}{b^{*}}=2,5 \cdot f_{1} \cdot f_{2} \cdot f_{3}$ \\
Kothyari vd. (2007) & $\frac{d_{s}}{z_{R}}=0,272 \sigma_{g}^{-1 / 2}\left(F{ }_{d}-F_{d \beta}\right)^{2 / 3} \log T$ \\
\hline$\frac{d_{s}}{b}$ & $=\alpha K\left(\frac{b}{d}\right)^{K}\left(\frac{y}{b}\right)\left(\frac{V}{V_{c}}-I_{v c}\right)$
\end{tabular}

Temiz su oyulması durumunda meydana gelen oyulmalarda oyulma derinliğinin ulaşabileceği en yüksek mertebe denge oyulma derinliği olarak tanımlanmıştır. Denge oyulma derinliğine ulaşılabilmesi için deneyler çok uzun süre almakta ve hatta günler boyunca sürebilmektedir. Melville ve Chiew (1999), denge oyulma derinliğine son 24 saatte meydana gelen oyulmanın ayak çapının \%5'inden büyük olmaması durumunda ulaşılmış olacağını belirtmiștir. Her ne kadar denge oyulma derinliğine ulaşılabilmesi için deneylerin günler

\section{Literatürdeki Mevcut Bağıntılar}

Literatürde denge oyulma derinliğini tahmin etmekte kullanılan bazı bağıntılar, Tablo 1'de verilmiștir.

Tablo 1'deki bağıntılarda $\mathrm{d}_{\mathrm{s}}$, denge oyulma derinliğini; $y$, yaklaşan akım derinliğini; $b$, ayak genişliğini; Fr, Froude sayısını; V, yaklaşan akım hızını ve $V_{c}$ taban malzemesi hareketi için ulaşılması gereken eşik hızını göstermektedir. $V_{c}$ kritik hız değeri, Melville (1999)'de verildiği gibi aşağıdaki şekilde hesaplanabilir: 


$$
\frac{V_{c}}{u_{c}}=5,75 \log \left(5,53 \frac{y}{d_{50}}\right)
$$

$\mathrm{Bu}$ ifadede $\mathrm{u}_{\mathrm{c}}$ kritik kayma h1zı olup, $\mathrm{d}_{50}$ medyan tane boyutu esas alınarak Shields diyagramından bulunabilir. Ancak pratik olması açısından Melville (1997), $\mathrm{u}_{\mathrm{c}}$ değerini hesaplamak için $u_{c}(\mathrm{~m} / \mathrm{s})$ ve $d_{50}(\mathrm{~mm})$ cinsinden olmak üzere Shields diyagramını aşağıdaki denklem takımına dönüştürmüştür:

$$
\begin{gathered}
u_{*_{c}}=0,0115+0,0125 d_{50}{ }^{1,4} \\
\text { eğer } 0,1 \mathrm{~mm}<\mathrm{d}_{50}<1 \mathrm{~mm} \mathrm{(13a)} \\
u_{*_{c}}=0,0305 d_{50,5}^{0,0,0065 d_{50}{ }^{-1}} \\
\text { eğer } 1 \mathrm{~mm}<\mathrm{d}_{50}<100 \mathrm{~mm} \mathrm{(13b)}
\end{gathered}
$$

Melville (1997)'in (6) bağıntısında $\mathrm{K}_{\mathrm{yw}}$ derinlik (y) boyutu faktörü, göreceli yaklaşan akım derinliğine $(\mathrm{y} / \mathrm{b})$ bağlı olarak tanımlanmıștır. Orta ayak için bu katsayı, $\mathrm{K}_{\mathrm{yb}}$ indisi ile gösterilmektedir.

$$
\begin{aligned}
& K_{y b}=2,4 b \text { eğer } b / y<0,7 \\
& K_{y b}=2 \sqrt{y b} \text { eğer } 0,7<b / y<5 \\
& K_{y b}=4,5 y \text { eğer } b / y>5
\end{aligned}
$$

$\mathrm{K}_{\mathrm{I}}$ akım şiddeti faktörü, üniform malzemeler için $\mathrm{K}_{\mathrm{I}}=\mathrm{V} / \mathrm{V}_{\mathrm{c}}$ olarak ifade edilmiştir. $\mathrm{K}_{\mathrm{d}}$ tane boyutu faktörü, göreceli tane çapına $\left(\mathrm{b} / \mathrm{d}_{50}\right)$ bağlı olarak tanımlanmıştır.

$$
\begin{aligned}
& K_{d}=0,57 \log \left(2,24 b / d_{50}\right) \quad ; b / d_{50} \leq 25 \\
& K_{d}=1 ; b / d_{50}>25
\end{aligned}
$$

$\mathrm{K}_{\mathrm{s}}$ ayak şekil faktörü, dairesel silindirik ve yuvarlak uçlu ayaklar için 1, kare uçlu ayaklar için 1,1, sivri uçlu ayaklar için 0,9 olarak önerilmiştir. $K_{\theta}$ ayak doğrultu faktörü, dairesel ayaklar için $\mathrm{K}_{\theta}=1$ olarak önerilmiştir. $\mathrm{K}_{\mathrm{G}}$ kanal geometrisi faktörü orta ayaklar için $\mathrm{K}_{\mathrm{G}}=1$ olarak önerilmiştir.

Richardson ve Davis (2001)'in bağıntısındaki $\mathrm{K}_{1}$ ve $K_{2}$ faktörleri sırasıyla $K_{s}$ ve $K_{\theta}$ 'ya eşit olup, $K_{3}$ ve $K_{4}$ faktörleri temiz su oyulması için 1 alınabilir.

Oliveto ve Hager (2002)'nin bağıntısındaki $\mathrm{N}=$ $\mathrm{K}_{\mathrm{s}}$ şekil faktörü; $\sigma_{\mathrm{g}}$ taban malzemesinin geometrik standart sapmasi; $F_{d}$, yoğunluk fark1 esaslı dane Froude sayısı $F_{d}=V /\left(g^{\prime} d_{50}\right)^{0,5}$; g' göreceli yer çekimi ivmesi $g^{\prime}=\left[\left(\rho_{s}-\rho\right) / \rho\right] g$; $\rho_{s}$ ve $\rho$ sirasiyla taban malzemesinin ve akışkanlık yoğunlukları, T göreceli zaman $T=$ $\left[\left(g^{\prime}-d_{50}\right)^{0,5} / z_{R}\right] t ; \quad \mathrm{zR}_{\mathrm{R}}$ referans uzunluğu $\left(y b^{2}\right)^{1 / 3}$.

Sheppard ve diğg. (2004)'in önerdiği bağıntıdaki $\mathrm{f}_{1}, \mathrm{f}_{2}$ ve $\mathrm{f}_{3}$ faktörleri, $\mathrm{b}^{*}=\mathrm{K}_{\mathrm{s}}$.b olmak üzere aşağıdaki verildiği gibidir:

$$
\begin{aligned}
& f_{1}=\tanh \left[\left(\frac{y}{b^{*}}\right)^{0,4}\right] \\
& f_{2}=1-1,75\left[\ln \left(\frac{V}{V_{c}}\right)\right]^{2} \\
& f_{3}=\left(\frac{b^{*} / d_{50}}{0,4\left(b^{*} / d_{50}\right)^{1,2}+10,6\left(b^{*} / d_{50}\right)^{-0,13}}\right)
\end{aligned}
$$

Kothyari vd. (2007)'nin bağıntısındaki $F_{d \beta}$, oyulma başlangıcı için yoğunluk farkı esaslı tane Froude sayısıdır ve dairesel köprü ayakları için aşağıdaki bağıntı yardımıyla hesaplanabilir:

$$
F_{d \beta}=\left[F_{d i}-1,26 \beta^{1 / 4}\left(\frac{R_{h}}{d_{50}}\right)^{1 / 6}\right] \sigma_{g}{ }^{1 / 3}
$$

Burada $\mathrm{R}_{\mathrm{h}}$ hidrolik yarıçaptır. $\mathrm{B}$ akarsu taban genişliği olmak üzere $\beta=b / B$ bağıntısıyla hesaplanabilir. $\mathrm{F}_{\mathrm{di}}, v$ kinematik viskozite ve $D_{*}$ boyutsuz tane çapi $D=\left(g^{\prime} v^{2}\right)^{1 / 3} d_{50}$ olmak üzere aşağıdaki denklem seti ile hesaplanabilir:

$$
\begin{aligned}
& F_{d i}=1,08 D_{*}^{1 / 12}\left(\frac{R_{h}}{d_{50}}\right)^{1,6} \text { eğer } D_{*} \leq 10 \\
& F_{d i}=2,33 D_{*}^{-0,25}\left(\frac{R_{h}}{d_{50}}\right)^{1,6} \text { eğer } 10<D_{*}<150(18 \\
& F_{d i}=1,65\left(\frac{R_{h}}{d_{50}}\right)^{1,6} \text { eğer } D_{*}>150
\end{aligned}
$$

Lai vd. (2009), bağıntılarındaki $\alpha$ ve $I_{v c}$ değerlerini sirasiyla 3,9 ve 0,4 olarak önermişlerdir. Burada $I_{v c}$ oyulmanın başlaması için gereken akım şiddeti $\left(\mathrm{V} / \mathrm{V}_{\mathrm{c}}\right)$ değeridir. Bağıntıdaki diğer katsayılar aşağıdaki şekilde hesaplanabilir: 


$$
\begin{gathered}
K\left(\frac{b}{d}\right)=0,398 \ln \left(\frac{b}{d_{50}}\right)-0,034\left[\ln \left(\frac{b}{d_{50}}\right)\right]^{2} \\
\text { ĕger } 1 \leq b / d_{50}<50 \\
K\left(\frac{b}{d}\right)=1 \text { eğer } b / d_{50} \geq 50 \\
K\left(\frac{y}{b}\right)=0,783\left(\frac{y}{b}\right)^{0,322}-0,106 \\
\text { eğer } 0<y / b<3 \\
K\left(\frac{y}{b}\right)=1 \text { eğer } y / b \geq 3
\end{gathered}
$$

\section{Deney Düzeneği}

Deneyler, 18,6 m uzunluğa, $0,80 \mathrm{~m}$ genişliğe ve $0,75 \mathrm{~m}$ derinliğe sahip dikdörtgen doğrusal bir kanalda gerçekleştirilmiştir. Kanal tabanı $25 \mathrm{~cm}$ kalınlıkta olacak şekilde $\mathrm{d}_{50}=3,47 \mathrm{~mm}$ medyan tane büyüklüğüne ve $\sigma_{\mathrm{g}}=1,39$ geometrik standart sapmaya sahip taban malzemesi ile kaplanmıştır. Deneylerde $4 \mathrm{~cm}, 8 \mathrm{~cm}, 15 \mathrm{~cm}$ ve $20 \mathrm{~cm}$ çaplarında 4 farklı dairesel ayak kullanılmıştır. Deney düzeneğinin genel görünümü Şekil la ve 1 b'de verilmiştir. Sedimentin granülometrik eğrisi, Şekil 2'de verilmektedir.

Akım kanala bir hız kontrol cihazına bağlı, maksimum debisi $100 \mathrm{~L} / \mathrm{s}$ olan bir pompa ile iletilmektedir. Hiz kontrol cihazı, bir bilgisayar programı yardımı ile pompa devir sayısını istenilen sürede istenilen değere getirebilmektedir. Kanalın mansabına ulaşan akım, buradan $27 \mathrm{~m}^{3}$ hacimli bir hazneye savaklanmakta ve devir daim ile yeniden kanala iletilmektedir.

6 saat süren deneyler süresince oyulma derinliği, köprü ayağı etrafina yerleştirilen UVP (Ultrasonic Velocity Profiler) transdüserleri ile zamana bağl1 olarak ölçülmüştür. Met-Flow firmasının ürettiği bu cihazın asıl amacı akustik yöntemle hiz ölçümüdür. Her ne kadar UVP algılayıcıları bir doğrultu boyunca hız profilini çıkarmak için kullanılmaktaysa da bu çalışmada tabandan yansıyan dalgalar değerlendirilerek, taban kotundaki değişimlerin ölçülmesinde kullanılmıştır. Cihazın ölçtüğü veriler eşzamanlı olarak bilgisayara kaydedilebilmektedir. Cihaza aynı frekanslı olmak koşuluyla, birden fazla transdüser bağlanabilmektedir. UVP transdüserleri, Şekil 3'te gösterildiği gibi köprü ayağı etrafina yerleştirilmiştir. UVP transdüserlerinin oyulma derinliğine olan etkisi ihmal edilmektedir.
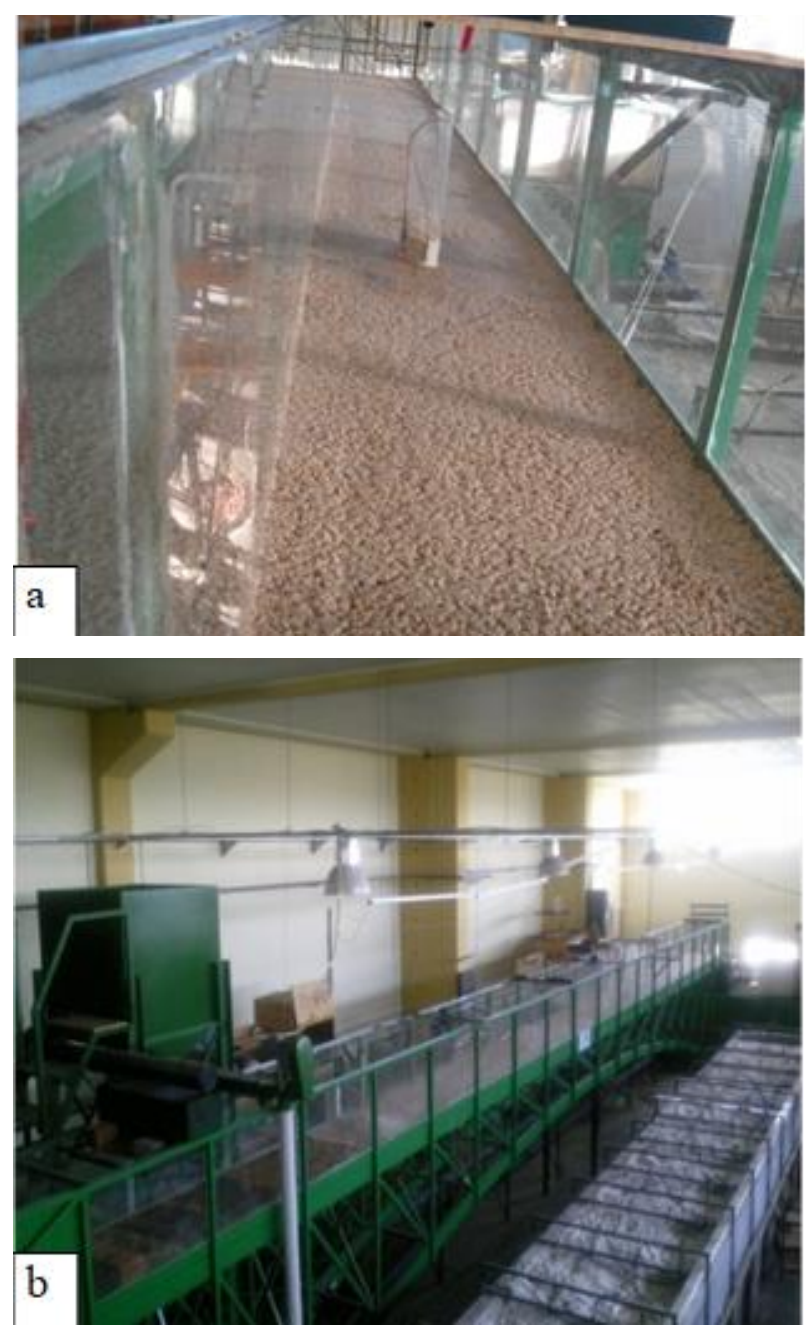

Şekil 1. a) ve b) Deney düzeneğinin genel görünüşü

\section{Figure 1. a) and b) General view of the experimental setup}

Yaklaşan akım derinliği, hassasiyeti $\pm 1 \mathrm{~mm}$ olan ULS (Ultrasonic Level Sensor) cihazı kullanılarak ölçülmüştür. Yaklaşan akım hızı, debimetre ile ölçülen debi ve ULS ile belirlenmiş olan yaklaşan akım derinlikleri yardımıyla hesaplanmıştır. 


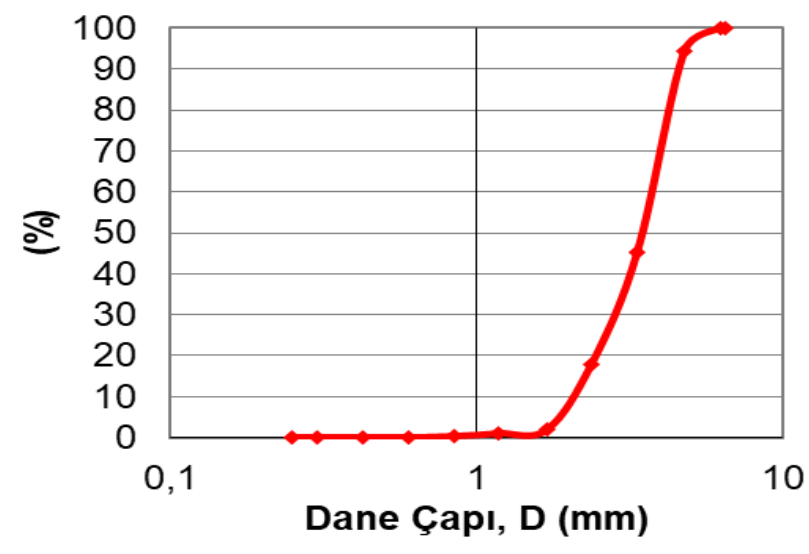

Şekil 2. Kullanılan taban malzemesinin dane dăğlım ĕgrisi

Figure 2. Granulometric curve of the bed material

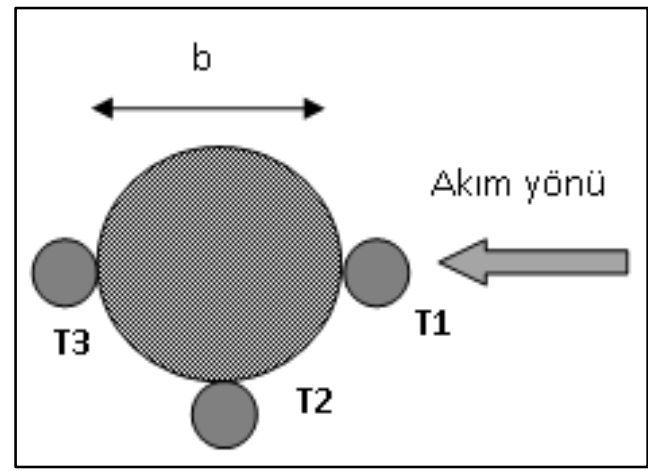

Şekil 3. Köprü ayă̆g etrafinda yerleştirilen transdüserler

Figure 3. Placement of the transducers around bridge pier

\section{Deneysel Bulgular}

Deneyler, $4 \mathrm{~cm}$ (D4), $8 \mathrm{~cm}$ (D8), $15 \mathrm{~cm}$ (D15) ve $20 \mathrm{~cm}$ (D20) çaplara sahip dairesel köprü ayakları ve üniform taban malzemesi kullanılarak farkl debilere sahip akımlarda gerçekleştirilmiş ve nihai oyulma derinlikleri elde edilmiştir. En yüksek oyulma derinliklerinin ayağın memba yönünde oluştuğu gözlenmiştir. Her bir deney sonucu elde edilen oyulma derinlikleri, deneye ait parametreler ile birlikte Tablo 2'de verilmektedir. Deney adının ilk rakamı ayak çapını, ikinci rakamı deney numarasını temsil etmektedir.

\section{Deneysel Bulguların İrdelenmesi ve Literatür ile Karşılaştırılması}

Deneysel bulgular, bir yandan farkl1 deney şartları göz önüne alınarak kendi aralarında yorumlanmış, diğer yandan da ölçülen değerler literatürde verilen formüller kullanılarak elde edilen sayısal değerlerle karşılaştırılmıştır. Şekil 4 'te bu çalışmanın sonucunda elde edilen akım şiddeti ile ölçülen boyutsuz oyulma derinliğinin değişimi gösterilmektedir. Şekilden de görüleceği gibi aynı köprü ayağı çapında akım şiddeti arttıkça oyulma derinliğinin arttığı gözlenmiştir. $15 \mathrm{~cm}$ çaplı köprü ayağının kullanıldığı bir deney sonrasına ait görsel Şekil 5 'te verilmiştir.

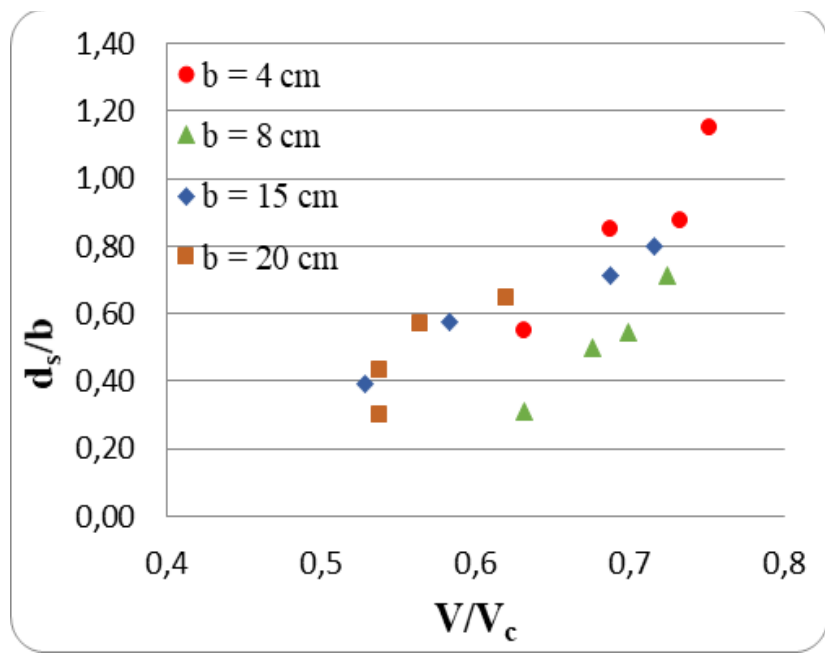

Şekil 4. Deneylerde elde edilen boyutsuz oyulma derinliğinin akım şiddeti ile değişimi

Figure 4. Variation of measured dimensionless scour depths with flow intensity

Ölçülen boyutsuz oyulma derinliklerinin göreceli dane boyutuna $\left(\mathrm{b} / \mathrm{d}_{50}\right)$ bağlı olarak değișimi Șekil 6'da verilmektedir. Melville (1997), oyulma derinliğinin, b/d50'nin 25 'ten büyük değerlerinde dane çapından bağımsız olduğunu söylemiştir. $\mathrm{Bu}$ değer Ettema (1980)'nın yaptığı çalıșma sonucunda 50 olarak verilmektedir. Şekil 6'da görüldüğü üzere $\mathrm{b} / \mathrm{d}_{50}>25$ değerlerinde oyulma derinliğinin etkilendiği görülmektedir. Deneysel bulguların Melville (1997)'in önerdiği sınır değerle uyuşmadığı tespit edilmiștir. 
Tablo 2. Ölçülen oyulma derinlikleri $d_{m}$ ve deneysel parametreler

Table 2. Measured scour depths $d_{m}$ and experimental parameters

\begin{tabular}{ccccccc}
\hline Deney No. & $\mathrm{b}(\mathrm{cm})$ & $\mathrm{Q}(\mathrm{L} / \mathrm{s})$ & $\mathrm{y}(\mathrm{cm})$ & $\mathrm{V} / \mathrm{V}_{\mathrm{c}}$ & $\mathrm{Fr}$ & $\mathrm{d}_{\mathrm{m}}(\mathrm{cm})$ \\
\hline D4-1 & 4 & 52 & 13,5 & 0,65 & 0,42 & 2,20 \\
D4-2 & 4 & 59 & 14,7 & 0,67 & 0,42 & 3,40 \\
D4-3 & 4 & 66 & 15,9 & 0,68 & 0,42 & 3,50 \\
D4-4 & 4 & 72 & 16,9 & 0,69 & 0,41 & 4,60 \\
D8-1 & 8 & 52 & 13,5 & 0,65 & 0,42 & 2,50 \\
D8-2 & 8 & 59 & 14,6 & 0,67 & 0,42 & 4,00 \\
D8-3 & 8 & 66 & 15,9 & 0,68 & 0,42 & 4,35 \\
D8-4 & 8 & 72 & 16,9 & 0,69 & 0,41 & 5,70 \\
D15-1 & 15 & 51 & 13,4 & 0,65 & 0,41 & 5,90 \\
D15-2 & 15 & 58 & 14,6 & 0,66 & 0,41 & 8,60 \\
D15-3 & 15 & 61 & 15,1 & 0,67 & 0,41 & 10,70 \\
D15-4 & 15 & 66 & 15,9 & 0,68 & 0,42 & 12,00 \\
D20-1 & 20 & 51,5 & 13,4 & 0,65 & 0,42 & 6,00 \\
D20-2 & 20 & 57 & 14,4 & 0,66 & 0,42 & 8,70 \\
D20-3 & 20 & 61 & 15,1 & 0,67 & 0,41 & 11,45 \\
D20-4 & 20 & 67,5 & 16,1 & 0,69 & 0,42 & 12,95 \\
\hline
\end{tabular}

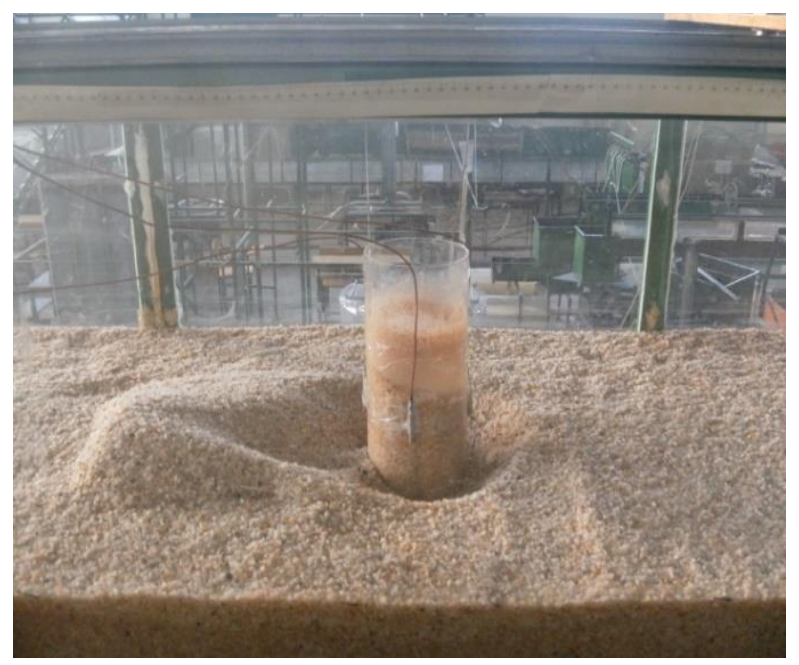

Şekil 5. Deney sonra oyulma çukurunun görünümü

Figure 5. View of the scour hole at the end of the experiment

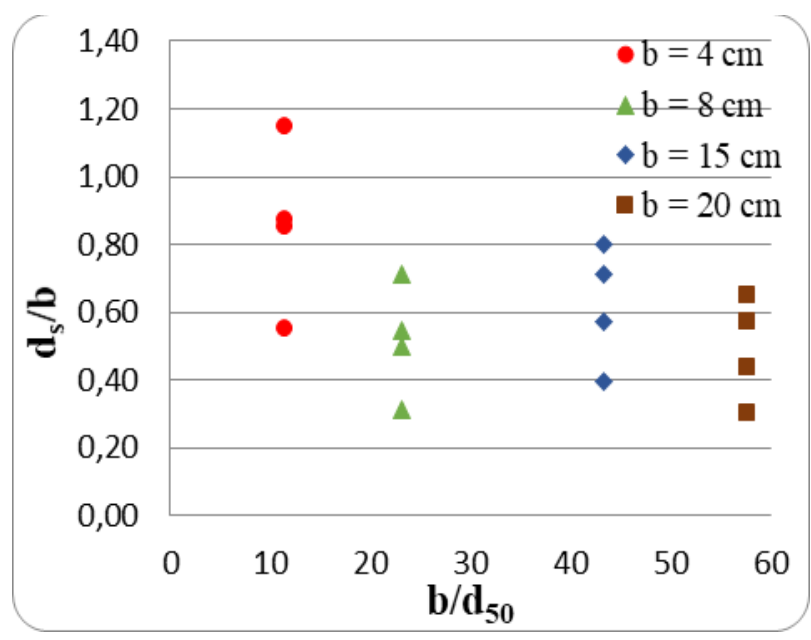

Şekil 6. Göreceli dane çapının oyulma derinliği üzerindeki etkisi

Figure 6. Effect of the relative grain size on scour depth

Şekil 7'de yoğunluk farkı esaslı dane Froude sayısının $\left(\mathrm{F}_{\mathrm{d}}\right)$ boyutsuz oyulma derinliğine olan etkisi verilmektedir. Grafikten de görüleceği gibi bu parametre arttıkça oyulma derinliği de artmaktadır. $\mathrm{Bu}$ eğilim tüm köprü ayak çapları için ortak bir özellik olarak görülmektedir. 


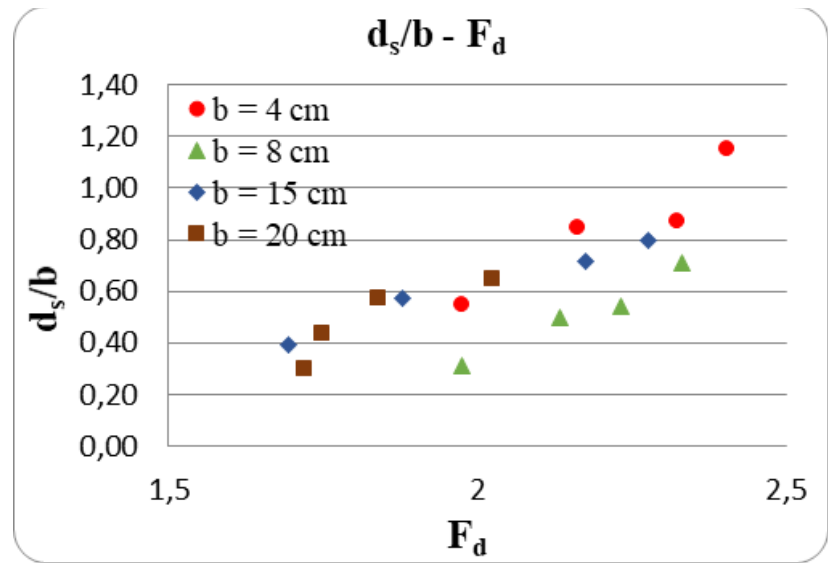

Şekil 7. Yoğunluk farkı esaslı dane Froude sayısının oyulma derinliği üzerindeki etkisi Figure 7. Effect of the densimetric particle Froude number on scour depth

Şekil 8'de ölçülen oyulma derinlikleri ile mevcut bağıntılardan elde edilen oyulma derinlikleri karşılaştırılmıştır. Lai vd. (2009) ve Kothyari vd. (2007)'nin verdiği bağıntıların, bu çalışmanın sonuçları ile en iyi mertebede uyumlu oldukları görülmektedir. Lai vd. (2009)'nin verdikleri bağıntıda, akım şiddeti $\left(\mathrm{V} / \mathrm{V}_{\mathrm{c}}\right)$, yaklaşan akım derinliği etkisi $(\mathrm{y} / \mathrm{b})$ ve göreceli tane çapının etkisini $\left(\mathrm{b} / \mathrm{d}_{50}\right)$ dikkate almışlardır. Kothyari vd. (2007) ise yoğunluk esaslı dane Froude sayısını $\left(F_{d}\right)$ ve oyulma başlangıcı için yoğunluk farkı esaslı dane Froude sayısını $\left(\mathrm{F}_{\mathrm{d} B}\right)$ göz önüne almışlardır.

$\mathrm{Bu}$ çalışmadan elde edilen 16 veri noktası ve çeşitli araştırmacilardan elde edilen 152 veri noktası (Tablo 3) ile bir regresyon analizi yapılmıştır. $\mathrm{Bu}$ analiz sonucunda 0,74 determinasyon katsayısı $\left(\mathrm{R}^{2}\right)$ ve \%20,34 saçılma indeksi (SI) ile bir denklem türetilmiştir:

$\frac{d_{s}}{b}=1,57\left(\frac{y}{b}\right)^{0,261} \ln \left(\frac{b}{d_{50}}\right)^{0,204}\left(\frac{V}{V_{c}}-I_{v c}\right)^{0,704}$

Tablo 3. Araştırmacılar ve regresyon analizinde kullanılan veri noktasi sayıları

Table 3. Researchers and their data points used in the regression analyses

\begin{tabular}{lc}
\hline Araştırmacı & Veri Noktas1 \\
\hline Dey vd. (1995) & 18 \\
Chang vd. (2004) & 4 \\
Melville ve Chiew (1999) & 81 \\
Mia ve Nago (2003) & 5 \\
Chabert ve Engeldinger (1956) & 12 \\
Yanmaz ve Altinbilek (1991) & 2 \\
\hline
\end{tabular}

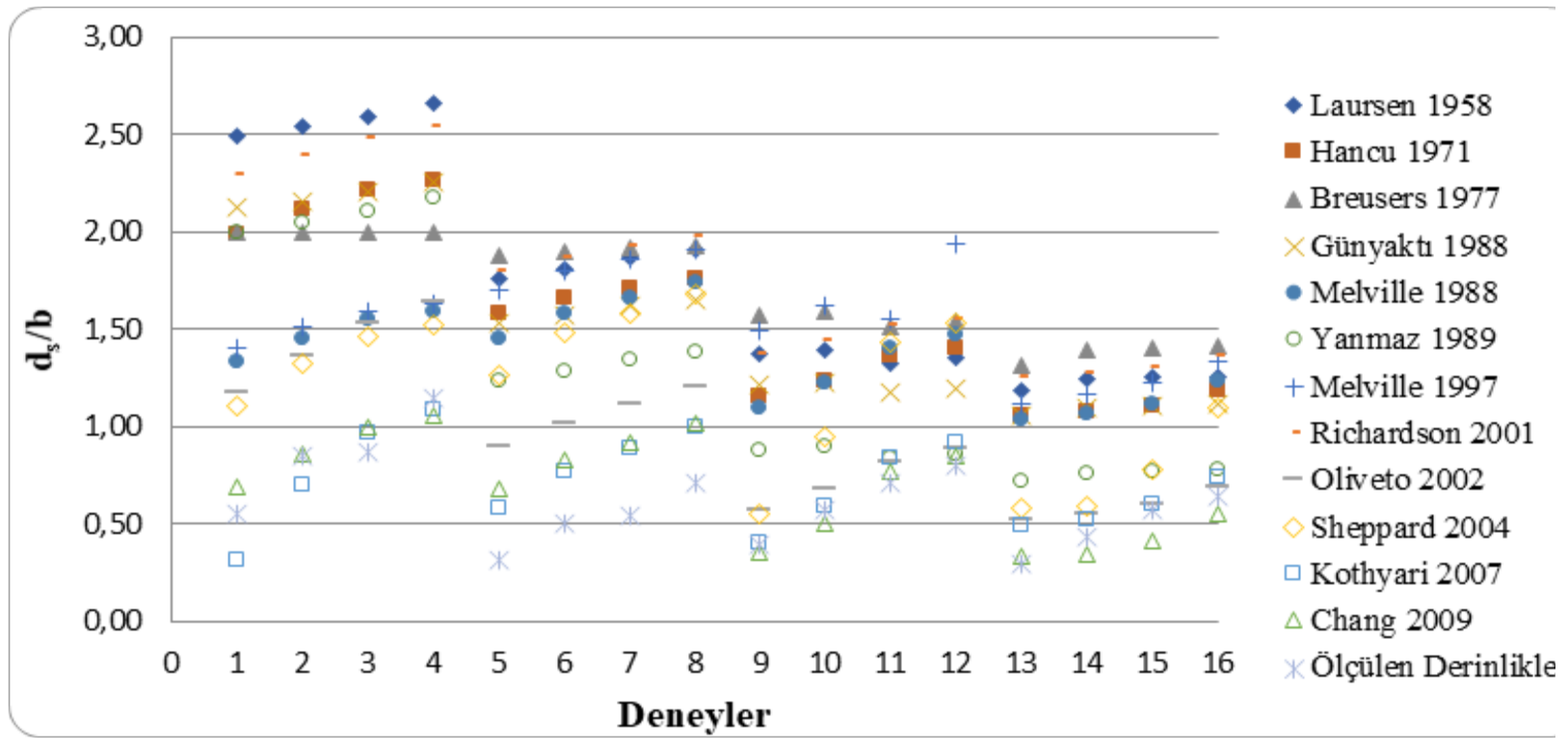

Şekil 8. Ölçülen oyulma derinlikleri ve mevcut bağıntılarla karşılaştırılması

Figure 8. Comparison of the measured scour depths and those obtained from the present equations. 
Oyulmanın başlaması için gerekli akım şiddeti değeri $\left(\mathrm{I}_{\mathrm{vc}}\right)$ 0,4 olarak göz önüne alınmıştır. Ölçülen boyutsuz oyulma derinlikleri ile denklem (20) ile hesaplanan boyutsuz oyulma derinlikleri Şekil 9'da verilmektedir.

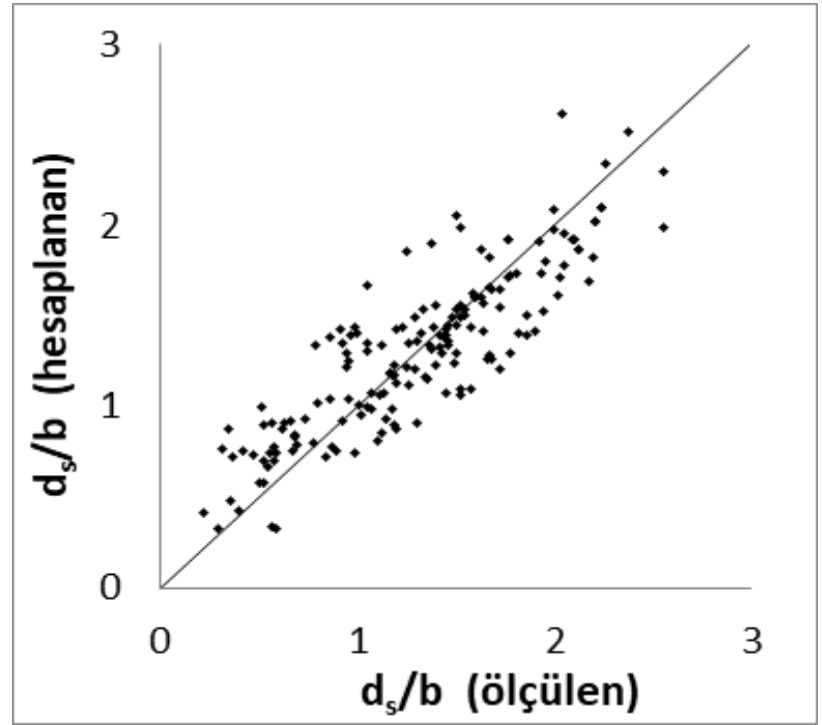

Şekil 9. Ölçülen ve hesaplanan boyutsuz oyulma derinliklerinin karşılaştırılması

Figure 9. Comparison of measured and calculated dimensionless scour depths

\section{Sonuçlar}

Deneyler esnasında mevcut bilgilere ve önceki çalışmalara uyumlu olarak, en büyük oyulmanın köprü ayağının memba bölgesinde oluştuğu ve oyulma sırasında akımın kopardığı malzemenin taşınarak mansap bölgesinde y1ğıldığg gözlenmiştir. Akım şiddeti, yoğunluk farkı esaslı dane Froude sayısı ve ayak çapı arttıkça oyulma derinliğinin arttığı gözlenmiştir.

Lai vd. (2009) ve Kothyari vd. (2007)'nin önerdiği bağıntıların bu çalışmanın sonuçları ile en iyi mertebede uyumlu oldukları görülmüştür. Yapılan regresyon analizi sonucu, köprü ayakları etrafinda meydana gelen nihai temiz su oyulmasını tahmin etme amaciyla bir denklem türetilmiş, istatistiksel olarak anlamlı olan determinasyon katsayısı $\left(\mathrm{R}^{2}=0,74\right)$ ve saçılma indeksi (SI $=\% 20,34)$ elde edilmiştir

\section{Teșekkür}

Yazarlar finansal destek için TÜBİTAK'a (proje numarası 109M637) teșekkür ederler.

\section{Kaynaklar}

[1] Breusers, H. N. C., Nicollet, G., Shen, H. W., (1977). Local scour around cylindrical piers, Journal of Hydraulic Resources, 15, 3, 211-252.

[2] Chang, W., Lai, J., Yen, C., (2004). Evolution of Scour Depth at Circular Bridge Piers, Journal of Hydraulic Engineering, 130, 9, 905-913.

[3] Chabert, J., Engeldinger, P., (1956). Etude des affouillements autour des piles de ponts, Serie A. Laboratoire National d'Hydraulique, 6, Quai Watier, Chatou, France.

[4] Chiew. Y. M., (1984). Local Scour at Bridge Piers, Doktora Tezi, The University of Auckland, Auckland.

[5] Dey, S., Bose, S., Sastry, G., (1995). Clear Water Scour at Circular Piers: a Model, Journal of Hydraulic Engineering, 121, 12, 869-876.

[6] Ettema, R. E., (1980). Scour at bridge piers, Rep. No. 236, School of Engineering, The University of Auckland, New Zealand.

Günyaktı, A., (1988). Köprü ayakları etrafında oyulma derinliğinin grafik yöntemle tayini, Mühendislik ve Çevre Bilimleri Dergisi, TÜBİTAK, 12, 1, 96-108.

[8] Hancu, S., (1971). Sur le calcul des affouillements locaux dams la zone des piles des ponts. Proc., 14th /AHR Congr., Int. Assn. for Hydr. Res. (IAHR), Paris, France, 3, 299-313.

[9] Kothyari, U. C., Hager, W. H., Oliveto, G., (2007). Generalized approach for clear-water scour at bridge foundation elements, Journal of Hydraulic Engineering, 133, 11, 1229-1240.

[10] Lai, J. S., Chang, W. Y., Yen, C. L., (2009). Maximum Local Scour Depth at Bridge Piers under Unsteady Flow, Journal of Hydraulic Engineering, ASCE, 135, 7, 609-614.

[11] Laursen, E. M., (1958). Scour at bridge crossings, Bull. No.8, Iowa Hwy. Res. Board, Ames, Iowa.

[12] Melville, B. W., (1975). Local scour at bridge sites, Doktora Tezi, The University of Auckland, Auckland.

[13] Melville, B. W., Sutherland A.J., (1988). Design Method for Local Scour at Bridge Piers, Journal of Hydraulic Engineering, 114, 10, 1210-1226.

[14] Melville, B. W., (1997). Pier and abutment scour: integrated approach, Journal of Hydraulic Engineering, 123, 2, 125-136.

[15] Melville, B., Chiew, Y., (1999). Time Scale for Local Scour at Bridge Piers, Journal of Hydraulic Engineering, 125, 1, 59-65. 
[16] Mia, M., Nago, H. (2003). Design Method of Time-Dependent Local Scour at Circular Bridge Pier, Journal of Hydraulic Engineering, 129, 6, 420-427.

[17] Oliveto, G., Hager, W. H., (2002). Temporal evolution of clear-water pier and abutment scour, Journal of Hydraulic Engineering, 128, 9, 811820.

[18] Oliveto, G., Hager, W. H., (2005). Further results to time-dependent local scour at bridge elements, Journal of Hydraulic Engineering, 131, 2, 97-105.

[19] Raudkivi, A. I., (1986). Functional trends of scour at bridge piers, Journal of Hydraulic Engineering, ASCE, 112, 1, 1-13.

[20] Richardson, E.V., Davis, S.R., (2001). Evaluating scour at bridges (4th Edition), Teknik Rapor, Federal Highway Administration Hydraulic Engineering Circular No. 18, FHWA NHI 01-001.

[21] Sheppard, D. M., Odeh, M., Glasser, T., (2004). Large scale clear-water local pier scour experiments, Journal of Hydraulic Engineering, 130, 10, 957-963.

[22] Yanmaz, A. M., (1989). Time dependent analysis of clear water scour around bridge piers, Doktora tezi, Orta Doğu Teknik Üniversitesi, Ankara, Türkiye.

[23] Yanmaz, A., Altinbilek, H. (1991). Study of TimeDepenbent Local Scour around Bridge Piers, Journal of Hydraulic Engineering, 117, 10, 1247-1268.

[24] Yanmaz, A.M., (2002). Köprü Hidroliği, Ankara: METU Press 


\section{Experimental Investigation of Final Scour Depths Around Circular Bridge Piers Under Clear Water Conditions}

\section{Extended Abstract}

To date, numerous studies have been carried out by various researchers on clear water scour around bridge piers. The development of local scouring around the bridge piers is a complex process, and although there is much work on this topic, it is still of interest to researchers. In this experimental study, final clear water scour around circular bridge piers under steady flow was investigated. On the one hand experimental findings were interpreted among themselves taking into account the different experimental conditions, on the other hand the measured scour depths were compared with the scour depths obtained using the equations given in the literature.

Experiments were carried out in a flume $18.6 \mathrm{~m}$ long, $0.8 \mathrm{~m}$ wide and $0.75 \mathrm{~m}$ deep constructed in the Hydraulic Laboratory of Civil Engineering Department of Dokuz Eylul University within the scope of TÜBITAK $109 M 637$ project. Uniform bed material having $3.47 \mathrm{~mm}$ median diameter was used during the experiments. Circular piers with $4 \mathrm{~cm}, 8$ $\mathrm{cm}, 15 \mathrm{~cm}$ and $20 \mathrm{~cm}$ diameters were tested under various steady discharges. Scour depths were measured by ultrasonic velocity profiler (UVP) device and flow depths were measured by ultrasonic level sensor (UltraLab ULS).
In accordance with the previous studies, it was observed that the highest scouring occurred in the upstream region of the bridge pier and the bed material that was eroded from scour hole was transported and stacked in the downstream region. It was also observed that scour depths increased with increase in flow intensity and densimetric particle Froude number. Relative grain diameter (b/d50) was found effective even after $b / d_{50}>25$.

Measured scour depths compared with calculated scour depths from 11 different equations. Results are given in literature in Figure 1. Scour depths calculated from the equations of Lai et al. (2009) and Kothyari et al. (2007) were found best fit with those obtained from the experiments.

A regression analysis was performed with 16 data points obtained from this study and 152 data points obtained from various researchers. An equation was proposed in order to predict final scour depth for clear water under steady flow. Meaningful statistical parameters obtained by comparison of measured scour depths and those calculated from the proposed equation.

Keywords: Local scour, bridge pier, clear water, steady flow.

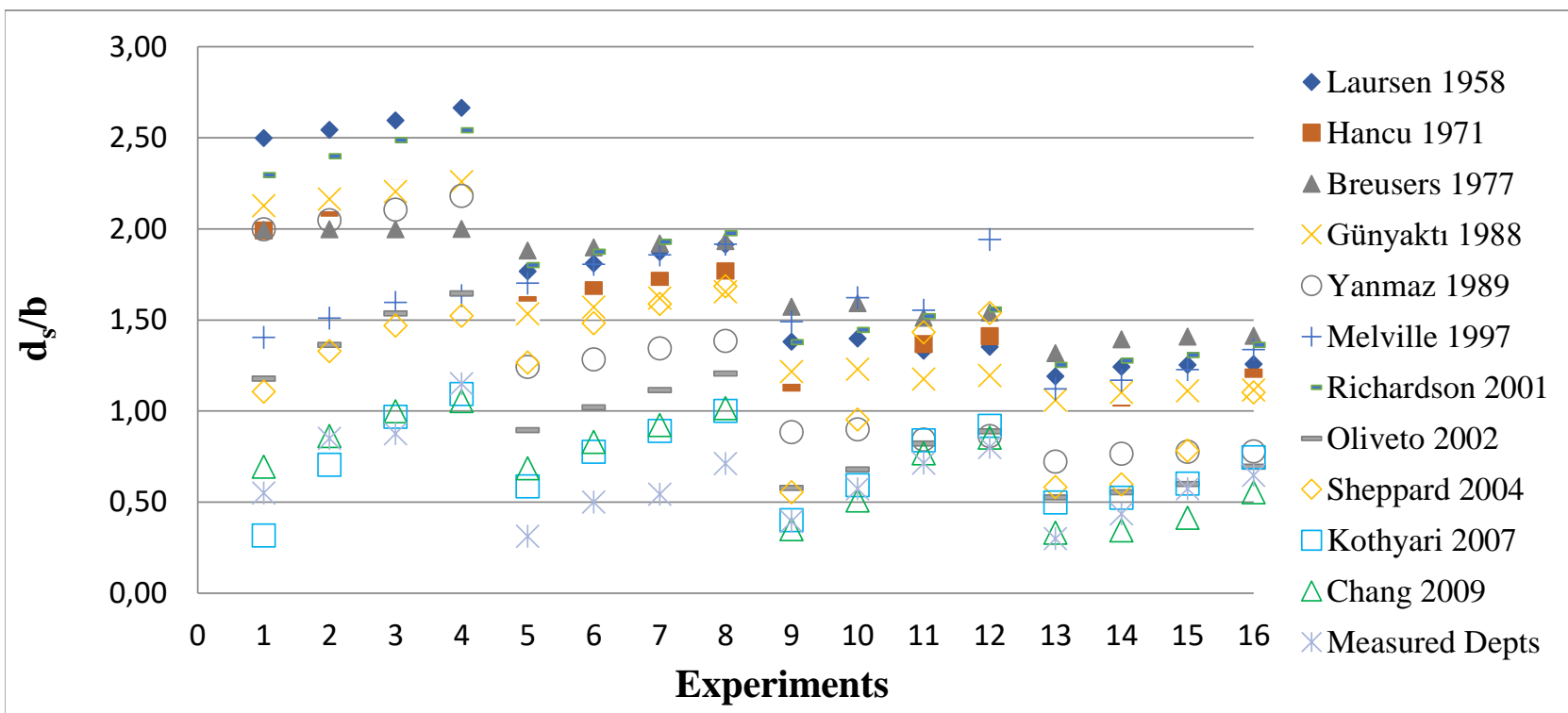

Figure 1. Measured scour depths and comparison with the present equations 